Original Article

\title{
Smooth-pursuit eye movements without head movement disrupt the static body balance
}

\author{
Sang-Yeob Kim, MS, OPT ${ }^{1)}$, Byeong-Yeon Moon, PhD, OPT ${ }^{1)}$, Hyun Gug Cho, PhD, OPT ${ }^{1 *}$ \\ 1) Department of Optometry, Kangwon National University: Dogye, Samcheok 245-907, Republic of \\ Korea
}

\begin{abstract}
Purpose] To investigate the changes of body balance in static posture in smooth-pursuit eye movements (SPEMs) without head movement. [Subjects and Methods] Forty subjects (24 males, 16 females) aged 23.24 \pm 2.58 years participated. SPEMs were activated in three directions (horizontal, vertical, and diagonal movements); the target speed was set at three conditions $\left(10 \%, 20 \%\right.$, and $30 \%$ ); and the binocular visual field was limited to $50^{\circ}$. To compare the body balance changes, the general stability (ST) and the fall risk index (FI) were measured with TETRAX. The subjects wore a head-neck collar and stood on a balance plate for $32 \mathrm{~s}$ during each measurement in three directions. SPEMs were induced to each subject with nine target speeds and directions. All measured values were compared with those in stationary fixation. [Results] The ST and FI increased significantly in all SPEMs directions, with an increased target speed than that in stationary fixation. In the same condition of the target speed, the FI had the highest value relative to diagonal SPEMs. [Conclusion] SPEMs without head movement disrupt the stability of body balance in a static posture, and diagonal SPEMs may have a more negative effect in maintaining body balance than horizontal or vertical SPEMs.

Key words: Smooth-pursuit eye movements, Body balance, Fall risk index
\end{abstract}

(This article was submitted Nov. 30, 2015, and was accepted Jan. 16, 2016)

\section{INTRODUCTION}

Body balance is a complex function dependent on sensory input through the vision, vestibular, and proprioceptive systems ${ }^{1)}$. Vision coupled with eye movements transmits complex sensory information to the central nervous system (CNS) from both the retinal and extra-retinal structures. Eye movements interfere with balance according to the kind of movement performed ${ }^{2}$. Humans have three visuomotor options (visual fixation, smooth-pursuit eye movements [SPEMs], and saccades) $)^{3)}$, and it had been previously demonstrated that eye movements can affect not only body balance but also the various functions of different types of eye movements. It is well known that visual fixation on a stationary object helps in minimizing body sway and increases the stability of static posture ${ }^{4-7)}$. Iwase et al. ${ }^{8)}$ and Uchida et al. ${ }^{9)}$ demonstrated that saccades reduce static postural sway as compared with stationary fixation. Furthermore, Brandt et al. ${ }^{10}$ ) have shown that the binocular pursuit of a moving target in a stationary visual environment significantly impairs static balance as compared with saccades. Schulman et al. ${ }^{3}$ ) observed that the time of maintaining balance on an unstable platform was longer during stationary fixation and saccades than during SPEMs. This shows that SPEM is the biggest factor contributing to the change of body balance.

Although some studies ${ }^{11-14)}$ have shown the effects of eye movements with head movement on body balance, the change of body balance caused by SPEMs without head movement has rarely been studied. In everyday life, any condition that causes restriction in head movements may occur, such as an orthopedic intervention (e.g., wearing a head-neck collar). Therefore, the present study was performed to investigate the negative effects of SPEMs without head movement on maintaining body balance in static posture.

\footnotetext{
*Corresponding author. Hyun Gug Cho (E-mail: hyung@kangwon.ac.kr)

(C)2016 The Society of Physical Therapy Science. Published by IPEC Inc.

This is an open-access article distributed under the terms of the Creative Commons Attribution Non-Commercial No Derivatives (by-nc-nd) License $<$ http://creativecommons.org/licenses/by-nc-nd/4.0/>.
} 


\section{SUBJECTS AND METHODS}

Forty subjects ( 24 males, 16 females) aged $23.24 \pm 2.58$ years participated in this study. All of them were healthy and had no neurological, otoneurological, or ophthalmological diseases. They were not taking any medications that might interfere with balance control and had a visual acuity of $>1.0$ in each eye. Subjects without a history of visuomotor impairment (or eye movement dysfunctions), anisometropia, amblyopia, nystagmus, or other abnormal binocular functions were also selected. All subjects understood the purpose of this study and provided informed consent to participate. This study was conducted in accordance with the ethical principles of the Declaration of Helsinki.

Before the body balance was assessed, the examiner corrected all subjects to emmetropia by means of subjective refraction with a manual phoropter (Phoropter 11625B, Reichert, Depew, NY, USA). The examiner subsequently asked the subjects to wear trial frames for correcting their ametropia and to wear a head-neck collar (Stifneck regular 980500, Laerdal Medical AS, Stavanger, Norway) for minimizing their head and neck movements during SPEMs. A visual display (LED TV AD55LB65S, LG, Seoul, Korea) was placed at a 0.6-m distance from the participant's eyes, and a black dot corresponding to a Landolt ring size of 20/40 was used as a fixation target made with a PC program (PowerPoint 2007; Microsoft, Redmond, WA, USA). The moving range of the target was adjusted to $70 \mathrm{~cm}$ on display for limiting the visual field to $50^{\circ}$.

To assess the influence of SPEMs on body balance, the TETRAX biofeedback system (Tetrax Portable Multiple System; Tetrax Ltd., Ramat Gan, Israel) was used, and changes in the general stability (ST) and the fall risk index (FI) were analyzed depending on the direction and velocity of SPEMs as compared with stationary fixation without any SPEMs. An increase in the values of the ST and FI indicates that postural stability was reduced and the chance of falling is greater, respectively. SPEMs were induced in three directions, horizontal (3-9 o'clock directions), vertical (12-6 o'clock directions), and diagonal (2-8 o'clock directions), in the ranges of the subject's binocular field of $50^{\circ}$. The target speed was set at three conditions $(10 \%, 20 \%$ s, and $30 \%$ s), and the target moved continuously in each direction within the limit of the field. The measured values in each direction with increment of the target speed were compared with those in a stationary condition without SPEMs. All trials were repeatedly measured for $32 \mathrm{~s}$, and the subjects were allowed a rest time of 1 min while adjustments to the other speed conditions are being made. When the moving target's direction was changed, a rest time of 10 min was allocated per subject.

For data analysis, repeated-measures analysis of variance was performed with SPSS for Windows (SPSS Inc., Chicago, IL, USA), and a value of $\mathrm{p}<0.05$ was considered significant.

\section{RESULTS}

The changes of ST depended on the target speed in each SPEM direction, as shown in Table 1. The ST increased significantly $(\mathrm{p}<0.05)$ with the increment of SPEM velocity in all moving directions of the target as compared with stationary fixation. The changes of FI depended on the target speed in each SPEM direction, as shown in Table 2. In all directions of SPEMs, the FI increased significantly $(\mathrm{p}<0.05)$ with the increment of target speed compared with that in stationary fixation. In the diagonal direction test of SPEMs, both ST and FI were higher than those in the horizontal and vertical directions.

\section{DISCUSSION}

SPEMs constantly maintain the image of a moving object in the fovea. Generally, SPEMs turn into saccadic movement when a target moves faster than $30^{\circ} \mathrm{s}$, and is accompanied by head movement when the target moves $>17^{\circ}$ from the principal line of fixation ${ }^{15}$. The head movements and accompanying eye movements are in complementary relations to maintain body balance. This study presents how SPEMs without head movement affect the ST and FI in static body balance.

The SPEMs in this study needed to accompany head movements because the range of the target movements was $50^{\circ}$ in all directions; however the subjects' head movement was restricted with the aid of a head-neck collar. The results showed that SPEMs without head movement remarkably increased the ST and FI with increasing target speeds in all of the horizontal, vertical, and diagonal directions ( $p<0.05$ as compared with stationary fixation). Lestienne et al. ${ }^{16)}$ reported that the increment of SPEM velocity induced an increase in the deviation of postural instability. While focusing on a stationary target, the peripheral visual field was not to be changed but to be fixed. On the contrary, because the target image is fixed in the fovea while the target moves, the other images perceived from the peripheral visual fields were simultaneously changed by the SPEMs ${ }^{17}$. Such perceptive changes of peripheral images by SPEMs can attenuate the visual signals for spatial orientation, and the stability of body balance may be disturbed. Although the CNS recognizes all changes and immediately activates the postural adjustments mechanism for spatial orientation ${ }^{16,18,19)}$, the rapid change of SPEM velocity may interrupt the postural adjustment mechanisms. Consequently, the stability of body balance is decreased, and the risk of falling increases. Ultimately, it indicates that the increments of ST and FI by increasing velocity of the SPEMs are rooted in the inappropriate spatial orientation resulting from maintaining the foveal image of the moving target ${ }^{20,21}$.

In a previous study ${ }^{22}$, visual blur induced by refractive errors was found to increase the FI. The FI value is especially higher in diagonal blur, which is induced by the incorrections of the oblique astigmatism more than the other blurs induced by 
Table 1. Changes in general stability (ST) with the directions of smooth-pursuit eye movements (SPEMs) with increments of target speed

\begin{tabular}{cccc}
\hline \multirow{2}{*}{$\begin{array}{c}\text { Target speeds } \\
(\% / \mathrm{s})\end{array}$} & Horizontal & Dertical & Diagonal \\
\cline { 2 - 4 } & $11.21 \pm 0.45$ & $11.21 \pm 0.45$ & $11.21 \pm 0.45$ \\
0 & $14.01 \pm 0.63^{*}$ & $14.03 \pm 0.65^{*}$ & $15.07 \pm 0.66^{*}$ \\
10 & $15.03 \pm 0.70^{*}$ & $15.13 \pm 077^{*}$ & $16.48 \pm 0.92^{*}$ \\
20 & $15.26 \pm 0.81^{*}$ & $15.94 \pm 0.80^{*}$ & $17.34 \pm 0.94^{*}$ \\
30 & $26.50 / 0.000$ & $37.00 / 0.000$ & $37.00 / 0.000$ \\
\hline
\end{tabular}

Data are expressed as mean \pm SE.

$* \mathrm{p}<0.05$ : significantly different from fixation on a stationary target (target speed 0 ) in least significant difference post-hoc analysis of repeated measures analysis of variance.

Table 2. Changes in the fall risk index (FI) according to the directions of smooth-pursuit eye movements (SPEMs) with increments of target speed

\begin{tabular}{cccc}
\hline $\begin{array}{c}\text { Target speeds } \\
(\%)\end{array}$ & Horizontal & Dertical & Diagonal \\
\cline { 2 - 4 } & $1.25 \pm 0.28$ & $1.25 \pm 0.28$ & $1.25 \pm 0.28$ \\
0 & $2.55 \pm 0.52^{*}$ & $2.60 \pm 0.59^{*}$ & $3.45 \pm 0.68^{*}$ \\
10 & $3.20 \pm 0.64^{*}$ & $3.75 \pm 0.65^{*}$ & $4.90 \pm 0.86^{*}$ \\
20 & $3.35 \pm 0.61^{*}$ & $4.75 \pm 0.72^{*}$ & $5.35 \pm 0.95^{*}$ \\
30 & $5.69 / 0.002$ & $10.24 / 0.000$ & $10.89 / 0.000$ \\
\hline
\end{tabular}

Data are expressed as mean \pm SE.

${ }^{*} \mathrm{p}<0.05$ : significantly different from fixation on a stationary target (target speed 0 ) in least significant difference post-hoc analysis of repeated measures analysis of variance.

the incorrections of the "with-the-rule" or the "against-the-rule" astigmatism while in stationary fixation in a static posture. These results suggest that the control mechanism for maintaining body balance is dissimilarly activated in each direction of the visual stimulus. If there was no consideration for SPEM velocity, this study shows that both ST and FI values in SPEMs diagonally were higher than in SPEMs horizontally and vertically. SPEMs induce the reactions of extraocular muscle proprioceptor, neck muscle reflexes, and tonic labyrinthine reflexes. Thereby, the control mechanism for body balance is more disoriented ${ }^{11,23,24)}$. Moreover, there is a high probability that tonic labyrinthine reflexes are more heavily activated with SPEMs without head movements when the target moves excessively from a principal line of fixation in a static posture, and it seems that the stimulus of diagonal SPEMs might be more sensitive than those of horizontal and vertical SPEMs for tonic labyrinthine reflexes.

In summary, when the velocity of SPEMs without head movements are increased, the stability of body balance is degraded and the risk of falling is increased. Additionally, in both visual blurs and eye movements, diagonal stimuli cause more confusion, affecting body balance, than do horizontal or vertical stimuli.

\section{REFERENCES}

1) Nashner LM, McCollum G: The organization of human postural movements: a formal basis and experimental synthesis. Behav Brain Sci, 1985, 8: 135-150. [CrossRef]

2) Séverac Cauquil A, Bessou M, Dupui P, et al.: Anteroposterior dynamic balance reactions induced by circular translation of the visual field. J Physiol Paris, 1996, 90: 53-62. [Medline] [CrossRef]

3) Schulmann DL, Godfrey B, Fisher AG: Effect of eye movements on dynamic equilibrium. Phys Ther, 1987, 67: 10541059. [Medline]

4) Ustinova K, Perkins J: Gaze and viewing angle influence visual stabilization of upright posture. Brain Behav, 2011, 1: 19-25. [Medline] [CrossRef]

5) Blanks RH, Fowler CG, Zizz CA, et al.: Postural adjustments produced by moving visual (horizontal optokinetic) patterns. J Am Acad Audiol, 1996, 7: 39-48. [Medline] 
6) Paulus WM, Straube A, Brandt T: Visual stabilization of posture. Physiological stimulus characteristics and clinical aspects. Brain, 1984, 107: 1143-1163. [Medline] [CrossRef]

7) Lord SR, Clark RD, Webster IW: Postural stability and associated physiological factors in a population of aged persons. J Gerontol, 1991, 46: M69-M76. [Medline] [CrossRef]

8) Iwase $\mathrm{Y}$, Uchida $\mathrm{T}$, Hashimoto M, et al.: The effect of eye movements on the upright standing in man. Agressologie, 1979, 20: 193-194.

9) Uchida T, Hashimoto M, Suzuki N, et al.: Effects of periodic saccades on the body sway in human subjects. Neurosci Lett, 1979, 13: 253-258. [Medline] [CrossRef]

10) Brandt T, Paulus W, Straube A: Vision and posture. In: Disorders of Posture and Gait. Amsterdam: Elsevier, 1986, pp $157-175$.

11) Fukushima J, Asaka T, Ikeda N, et al.: Postural control during downward head movements in young subjects. J Phys Ther Sci, 2007, 19: 205-212. [CrossRef]

12) Waterston JA, Barnes GR, Grealy MA, et al.: Coordination of eye and head movements during smooth pursuit in patients with vestibular failure. J Neurol Neurosurg Psychiatry, 1992, 55: 1125-1131. [Medline] [CrossRef]

13) Gauthier GM, Vercher JL: Visual vestibular interaction: vestibulo-ocular reflex suppression with head-fixed target fixation. Exp Brain Res, 1990, 81: 150-160. [Medline] [CrossRef]

14) Fukushima J, Asaka T, Fukushima K: Postural changes during eye-head movements. Prog Brain Res, 2008, 171: 335338. [Medline] [CrossRef]

15) Bahill AT, Adler D, Stark L: Most naturally occurring human saccades have magnitudes of 15 degrees or less. Invest Ophthalmol, 1975, 14: 468-469. [Medline]

16) Lestienne F, Soechting J, Berthoz A: Postural readjustments induced by linear motion of visual scenes. Exp Brain Res, 1977, 28: 363-384. [Medline]

17) White KD, Post RB, Leibowitz HW: Saccadic eye movements and body sway. Science, 1980, 208: 621-623. [Medline] [CrossRef]

18) Lee DN, Aronson E: Visual proprioceptive control of standing in human infants. Percept Psychophys, 1974, 15: 529532. [CrossRef]

19) Wapner S, Witkin HA: The role of visual factors in the maintenance of body-balance. Am J Psychol, 1950, 63: 385-408. [Medline] [CrossRef]

20) Dichgans J, Brandt TH: Visual-vestibular interaction: Effects on self-motion perception and postural control. In: Held R, et al (eds.), Handbook of Sensory Physiology: Perception. New York: Springer-Verlag New York Inc, 1978, pp 756-803.

21) Turvey MT: Modes of perceiving: Abstracts, comments, and notes. In: Pick HL Jr, Saltzman E (eds). Modes of Perceiving and Processing Information. Hillsdale: Lawrence Eribaum Associates, 1978, pp 205-224.

22) Kim SY, Moon BY, Cho HG: Changes in falling risk depending on induced axis directions of astigmatism on static posture. J Phys Ther Sci, 2015, 27: 1971-1973. [Medline] [CrossRef]

23) André-Deshays C, Berthoz A, Revel M: Eye-head coupling in humans. I. Simultaneous recording of isolated motor units in dorsal neck muscles and horizontal eye movements. Exp Brain Res, 1988, 69: 399-406. [Medline]

24) Corneil BD, Olivier E, Munoz DP: Visual responses on neck muscles reveal selective gating that prevents express saccades. Neuron, 2004, 42: 831-841. [Medline] [CrossRef] 